\title{
Linking genotype to cell function in chronic inflammation: analysis of the IL-23/Th17 axis in spondylarthropathy
}

\author{
M Roumier ${ }^{1 *}$, M Coffre ${ }^{1}$, H Law ${ }^{2}$, C Salliot $^{3}$, M Dougados ${ }^{3}$, E Bianchi ${ }^{1}$, L Rogge R $^{1,2}$ \\ From 5th European Workshop on Immune-Mediated Inflammatory Diseases \\ Sitges-Barcelona, Spain. 1-3 December 2010
}

For two decades, Th1 cells have been implicated in the pathogenesis of chronic inflammatory diseases. This notion has been challenged by the discovery of IL-23 and Th17 cells as key players in mouse inflammatory disease models. Furthermore, recent genome wide association studies have found a strong association between spondylarthropathy (SpA, a group of chronic inflammatory rheumatisms) and the presence of single nucleotide polymorphisms at the $I L-23 R$ locus.

Our aim is to study the role of the different $C D 4^{+}$ $\mathrm{T}$ cell subsets in SpA and to determine whether genetic variation at $I L 23 R$ affects IL-23 signaling and $\mathrm{CD} 4^{+}$ $\mathrm{T}$ cell function.

To address these questions, we analyzed secretion of inflammatory cytokines and expression of Th17 and Th1 marker genes by $\mathrm{CD} 4^{+} \mathrm{T}$ cells after stimulation in the presence or absence of IL-23. We also genotyped three SNPs at the $I L 23 R$ locus, highly associated with SpA. The minor allele of SNP rs1004819 is positively associated with disease (more frequent in the disease cohort). In contrast, the minor allele of SNPs rs11209026 and rs1343151 are "protective" (less frequent in the disease cohort).

We found that $\mathrm{CD} 4^{+} \mathrm{T}$ cells from patients carrying the positively associated minor allele secreted more IFNg, IL17A and IL17F. In contrast, secretion of these cytokines was decreased in patients carrying a protective minor allele.

Further support for critical role of these SNPs at IL23R locus on $\mathrm{CD}^{+} \mathrm{T}$ cell function comes from gene expression analysis. We observed that patients carrying the positively associated minor allele expressed higher levels of Th1 and Th17 marker genes whereas patients carrying a protective minor allele expressed lower levels of these genes.

Our results suggest that genetic variation at the IL23R locus strongly affects $\mathrm{CD} 4^{+} \mathrm{T}$ cell function in spondylarthropathy, and provide a link between genotype and pathology.

\section{Author details}

${ }^{1}$ Immunoregulation Unit and CNRS URA 1961, Institut Pasteur, Paris, France. ${ }^{2}$ Center for Human Immunology, Institut Pasteur, Paris, France. ${ }^{3}$ Service de Rhumatologie B, Hôpital Cochin, Paris, France.

Published: 25 November 2010

doi:10.1186/1479-5876-8-S1-O2

Cite this article as: Roumier et al:: Linking genotype to cell function in chronic inflammation: analysis of the IL-23/Th17 axis in

spondylarthropathy. Journal of Translational Medicine 2010 8(Suppl 1):O2.

${ }^{1}$ Immunoregulation Unit and CNRS URA 1961, Institut Pasteur, Paris, France

Full list of author information is available at the end of the article 